FEDERAL RESERVE BANK OF NEW YORK

\title{
EGONOMICPOLICYREVIEW
}

SHORTER ARTICLE

\section{How Did THE FED FundS \\ MARKET CHANGE \\ WHEN EXCESS RESERVES \\ WERE ABUNDANT?}

John P. McGowan and Ed Nosal 


\title{
How Did The Fed Funds MARKeT Change WHEN EXCESS RESERVES WERE ABUNDANT?
}

\author{
John P. McGowan and Ed Nosal
}

\section{OVERVIEW}

- The authors compare the Federal Reserve's monetary policy framework pre-crisis, when reserves were scarce, with its framework post-crisis through early 2018 , when reserves were abundant, and analyze the related changes in the federal funds market.

- Pre-crisis, the fed funds market was active and banks were the key participants. No interest was paid on reserves and the effective fed funds rate (EFFR) typically exhibited some day-to-day volatility. Post-crisis, fed funds market activity declined and foreign banking organizations (FBOs) and Federal Home Loan Banks (FHLBs) were the key participants. The Fed started paying interest on reserves in 2008 and day-to-day EFFR volatility decreased.

- The authors show that in the post-crisis period the EFFR consistently fell within the FOMC's target range and remained well connected with other overnight funding rates.
$\mathrm{T}$ he Federal Open Market Committee (FOMC) uses the federal funds rate as its policy rate to convey the stance of monetary policy, and has done so for decades. Nominal changes in the rate are expected to be transmitted broadly to other financial markets to have the desired effect on overall employment and inflation expectations in the United States.

Prior to the 2007 financial crisis, trading in the fed funds market was dominated by banks. ${ }^{1}$ Banks managed the balances-or reserves-of their Federal Reserve accounts by buying these balances from, or selling them to, each other. These exchanges between holders of reserve balances at the Fed are known as fed funds transactions. The amount of excess reserves in the banking system - total reserves minus total required reserves-was very small and banks actively traded fed funds in order to keep their reserves close to the required amount. When a bank's reserves exceeded what was required, it sold fed funds; when it fell short, it bought fed funds. Starting in 2008, the amount of excess reserves in the banking system increased dramatically, first with the Fed's provision of liquidity in response to the financial crisis, then with large-

\footnotetext{
Ed Nosal is a vice president and senior economist at the Federal Reserve Bank of Atlanta. John P. McGowan is an assistant vice president and policy advisor at the Federal Reserve Bank of New York.Email:ed.nosal@atl.frb.org; johnp.mcgowan@ny.frb.org.
}

The views expressed in this article are those of the authors and do not necessarily reflect the position of the Federal Reserve Bank of New York or the Federal Reserve System. To view the authors' disclosure statements, visit https://www.newyorkfed.org/research lepr/2020/epr_2020_fed-funds-functioning_mcgowan. 
scale asset purchases conducted by the Fed's System Open Market Account (SOMA). This increase in reserves resulted in a fed funds market that looked quite different than it did pre-crisis.

In this article, we describe conditions in the fed funds market that prevailed in the post-crisis "abundant reserves" period. We define this period as starting in 2010 and ending in early 2018, a few months after the FOMC began to redeem assets in the SOMA portfolio, which in turn reduced the level of reserves. In particular, we note that the very large increase in excess reserves in the post-crisis period changed both the types of participants that were active in the fed funds market and their motivations for participating. We also observe that day-to-day volatility in the effective federal funds rate (EFFR) decreased significantly in this period. ${ }^{2}$ In light of these changes, we examine whether the EFFR remained well connected to other short-term wholesale funding rates.

\section{Reserves Supply and Demand in the Pre-Crisis Monetary Policy Framework}

The hallmark of the Fed's pre-crisis monetary policy framework was an extremely low level of excess reserves in the banking system. To implement the FOMC's policy framework, the trading desk for the SOMA (the "Desk") conducted short-term open market operations in the repo (repurchase) market on a near-daily basis. These short-term open market operations would either increase or decrease the amount of reserve balances in the banking system so that, at least in expectation, banks would trade with one another at rates that were at, or very close to, the desired target of the policy rate. The size of each open market operation was based on an assessment of reserves supply and demand for that day, which the Desk made in collaboration with the Monetary Affairs division of the Federal Reserve Board.

By design, the target level of reserves in the pre-crisis framework exceeded the amount needed to meet reserve requirements by only a very small amount. ${ }^{3}$ Because the Fed did not compensate banks for their reserve balances, it was costly for banks to hold excess reserves. The Desk's operating framework limited this cost burden, however, as the Desk tried to supply the quantity of reserves demanded at the target rate. Demand for reserves was typically only slightly higher than the amount required to meet reserve requirements. Individual banks had an incentive to minimize their reserve holdings subject to meeting reserve requirements (computed as an average over a two-week maintenance period) while still maintaining positive end-of-day balances in their reserve accounts at the Fed. As a consequence, large banks typically had a presence on both sides of the fed funds market, buying and selling, because they needed this flexibility to optimize their reserve holdings at the Fed on a daily basis. Hence, the very low level of excess reserves in the system resulted in an active fed funds market.

Also by design, the curve of the required level of reserves always fell on the steep part of a (representative) bank's demand curve for reserves, as illustrated in Exhibit 1. Because the EFFR is determined by the intersection of the supply and demand curves, in the pre-crisis framework of scarce excess reserves the Desk was able to change the EFFR by varying the supply of reserves on this part of the demand curve, as the exhibit shows.

As noted previously, the Fed's pre-crisis framework relied on Desk forecasts of both reserve demand and reserve supply. The latter consisted of forecasting changes to the Fed's balance 
ExHibit 1

Reserves Supply and Demand in the Pre-Crisis Period

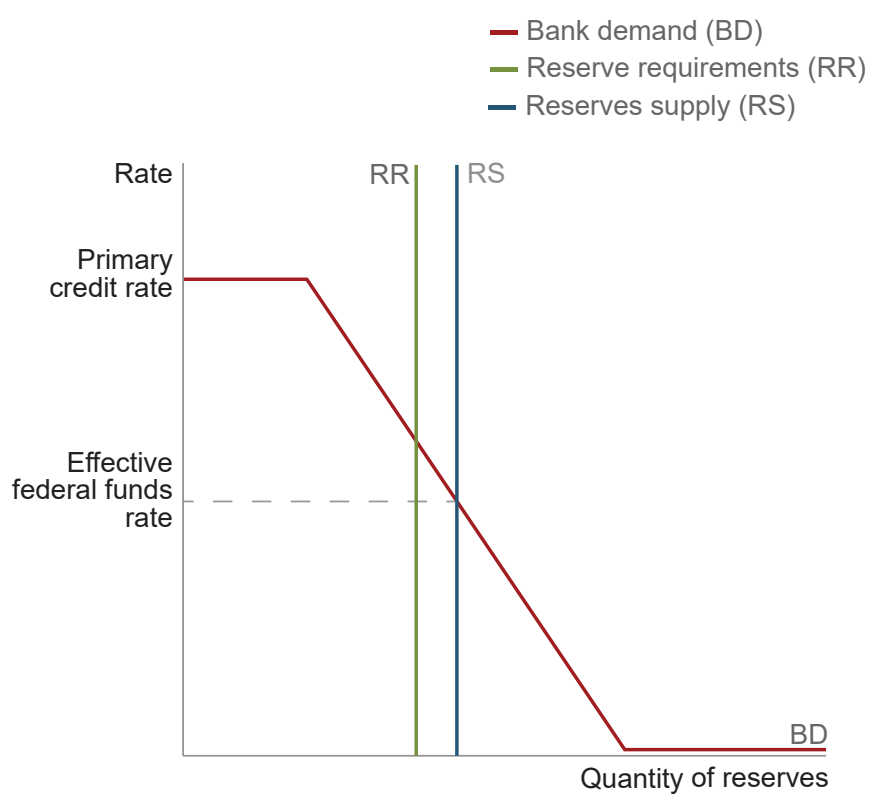

sheet that were outside the Desk's control-the so-called "autonomous factors." ${ }^{4}$ Since forecasts are always subject to errors and realized changes in reserve supply will tend to equal the forecasted change on average, on any particular day the actual change can be either greater than or less than the forecasted change. A negative supply forecasting error-measured as the difference between the actual provision of reserves and the forecasted amount-would result in too few reserves in the system, potentially prompting an unwelcome increase in the EFFR or borrowing from the discount window, or both. Conversely, a positive forecast error would result in too many reserves in the system, potentially prompting an unwelcome decline in the EFFR. Fortunately, this unavoidable exposure to forecast errors typically did not generate a large amount of EFFR volatility pre-crisis, since reserve requirement accounting allows banks to smooth their required reserve holdings over a two-week reserve maintenance period. This approach meant that supply forecast errors were generally impactful only on reserve maintenance period settlement days. ${ }^{5}$

\section{Reserves Supply and Demand in the Post-Crisis Abundant Excess Reserves Monetary POLICY FrameWORK}

In contrast, the post-crisis environment from 2010 to March 2018 was characterized by an abundance of excess reserves, with reserve balances being remunerated at the interest on excess reserves (IOER) rate. Since reserves during this period were significantly greater than what was required, the supply of reserves curve intersects the bank reserve demand curve on 
Exнiвiт 2

Reserves Supply and Demand in the Post-Crisis Period

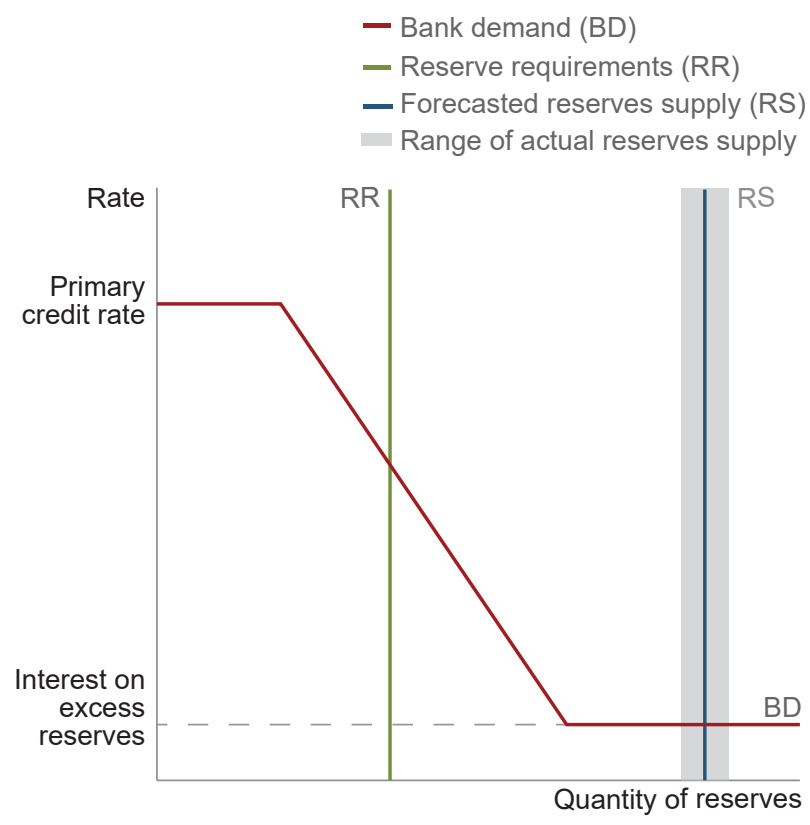

the flat part, as illustrated in Exhibit 2. With the supply of reserves residing on the far-right flat part of the demand curve, forecast errors have essentially no impact on the fed funds rate. That is, as illustrated in the exhibit, small deviations from the forecasted reserve supply curve will not affect the EFFR, which equals the IOER rate, in a perfectly competitive market.

With abundant reserves, banks rarely need to borrow reserves to meet reserve requirements or to offset an unexpected outflow of deposits precisely because, on average, bank reserve holdings far exceed what is required. Furthermore, IOER compensation on end-of-day reserve balances means that banks no longer have a significant opportunity cost associated with holding large end-of-day balances at the Fed. When excess reserves are abundant, banks are willing to lend fed funds at rates that are at or above the IOER rate. Conversely, they are willing to borrow in the fed funds market only when rates are at or below IOER compensation. As a result, in a perfectly competitive market, the EFFR will equal the IOER rate, where supply equals demand.

\section{Key Market Players in the Abundant Excess Reserves Period}

In the post-crisis abundant excess reserves environment, the amount of bank-to-bank lending in the fed funds market was quite small. Instead, lending in the fed funds market became dominated by the Federal Home Loan Banks (FHLBs). These institutions have accounts at 
Exнівіт 3

Supply of Reserves by Federal Home Loan Banks
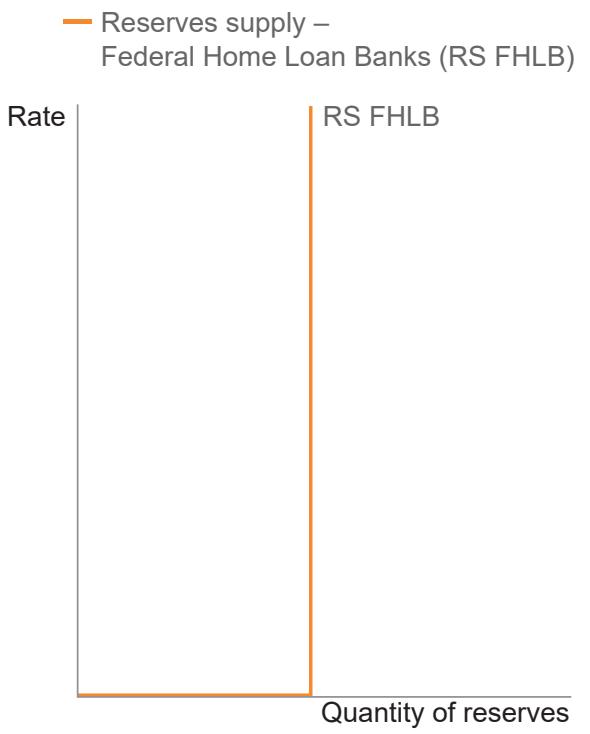

the Fed, which allows them to trade fed funds, but they are ineligible to receive IOER compensation (see Box 1). Of note, FHLB balances at the Fed do not enter the banking system and are, therefore, not part of the supply of banking reserves. As a result, FHLB balances behave in a manner similar to that of other non-reserve account holders at the Fed, such as the foreign repo pool or the Treasury General Account (TGA). ${ }^{6}$ These balances do become reserves of the banking system when they are invested in the private sector. Foreign official accounts invest in the overnight selected deposit and Eurodollar time deposit markets, and the FHLBs invest in the fed funds market. ${ }^{7}$ The U.S. Treasury, however, does not invest in either the fed funds or Eurodollar markets.

During the first part of the abundant excess reserves period, the supply of reserves provided by FHLBs to the banking sector can be thought of as a line that is horizontal at a zero fed funds rate up to the FHLBs' total holdings of reserves and then vertical at that point (see Exhibit 3). The horizontal part of the line reflects the idea that FHLBs are indifferent between lending and not lending at a zero fed funds interest rate; the vertical part reflects that the FHLBs will want to lend out all of their Fed balances when the fed funds rate exceeds zero.

The rationale for borrowing in the federal funds market also changed during the abundant reserves period. Such borrowing became dominated by foreign banking organizations (FBOs), which used the market as a source of funding and arbitrage profit (see Box 1). As such, the fed funds market was not typically used to make adjustments to banks' reserve holdings vis-à-vis their required holdings since reserve holdings far exceeded what was required. 
Box 1

Who Were the Major Participants in the Fed Funds Market When Excess Reserves Were Abundant?

\section{Lenders - Federal Home Loan Banks}

The Federal Home Loan Bank system was created by Congress in 1932 to facilitate financing in the U.S. housing market. The FHLBs accomplish this mission by lending to banks that lend in the U.S. housing market. Loans from the FHLBs are called advances. To receive an advance, banks must become members of the lending FHLB, and the advances are typically secured by U.S.-based real estate collateral. The FHLBs fund the advances by issuing securities. FHLBs maintain liquid assets, or buffers, to ensure timely repayment of their security liabilities when due. FHLB liquidity buffer assets typically consist of fed funds sold, Treasury bill securities, and Treasury reverse repo investments. FHLB liquidity buffers also serve as a reserve of liquidity that can be drawn upon to grant member advances on a timely basis.

Because FHLBs are not deposit-taking institutions, they are not subject to reserve requirements and thus are ineligible to earn IOER from the Fed. Since they are not eligible for IOER, FHLBs are challenged in their efforts to obtain interest income on their liquidity pools. FHLBs have a strong motivation to sell fed funds, since whatever rate they obtain on fed funds transactions is greater than the zero compensation they would receive on any end-of-day balances held in their accounts at the Fed.

\section{Borrowers - Foreign Banking Organizations}

In the post-crisis environment of abundant reserve balances, most fed funds borrowing transactions are motivated by "IOER arbitrage"-borrowing overnight at a rate below the IOER rate, leaving the funds at the Federal Reserve overnight to earn the IOER rate, and earning a positive spread on the transaction. Foreign banking organizations (FBOs) currently have a large presence in the fed funds market because of their borrowing advantage over domestic banking institutions. Since FBOs do not offer retail deposits, they are exempt from paying Federal Deposit Insurance Corporation (FDIC) insurance assessments, which all domestic banks must pay. The FDIC methodology for calculating these assessments changed in the post-crisis period. They are now based on the size of a bank's balance sheet and not on the bank's deposit liabilities, as they were pre-crisis. Borrowing costs are reduced if assessments are lower; in the case of FBOs they are zero.

One motivation for FBOs to borrow in the fed funds market is to maintain relationships with FHLB lenders. Unlike domestic banks, FBOs lack a natural U.S. dollar deposit base and they are therefore interested in maintaining a borrowing presence in U.S. wholesale funding markets. Although they generally are more interested in borrowing in tenors longer than overnight, FBOs are willing to engage in overnight fed funds transactions as long as they can earn a "reasonable" spread. FBO borrowers do not have a consensus on what constitutes a reasonable spread, but indications are that IOER arbitrage starts to become less attractive when the spread is five basis points or less. 
Exнівіт 4

Equilibrium in the Fed Funds Market in the Post-Crisis Period
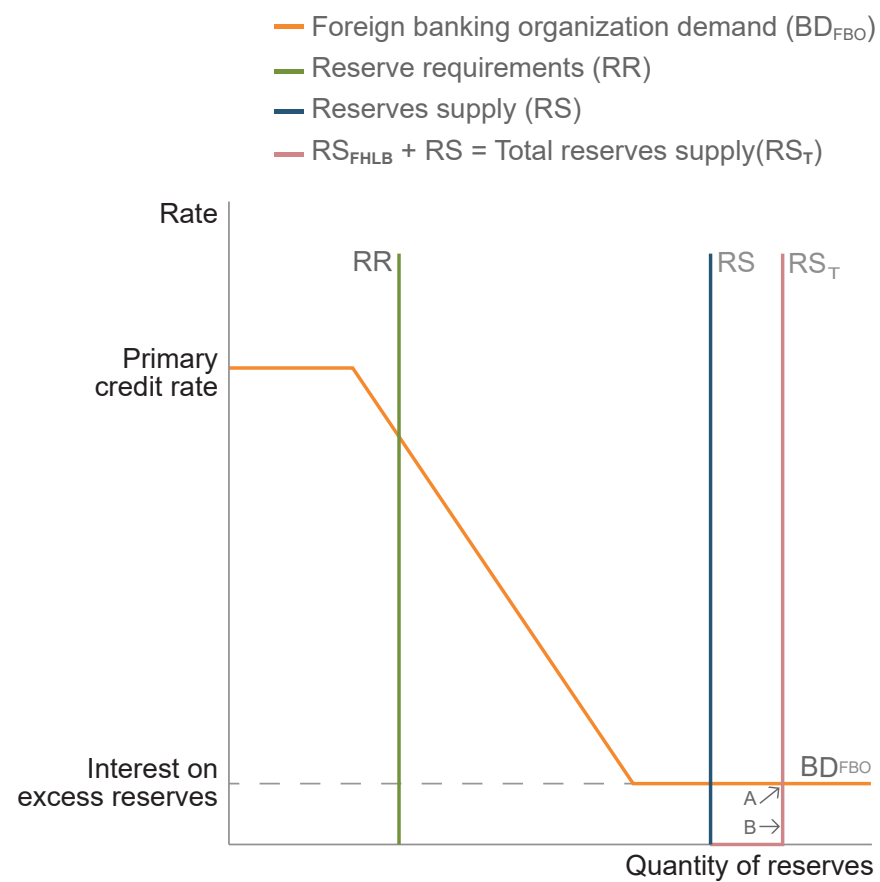

\section{Fed Funds Market Functioning in the Post-Crisis Abundant Excess Reserves FrameWORK}

\subsection{The Early Post-Crisis Years: 2010-13}

If the fed funds market is perfectly competitive, then the equilibrium EFFR should equal the IOER rate. This relationship is illustrated by point $\mathrm{A}$ in Exhibit 4, where the total reserve supply curve-which includes reserves supplied by banks and FHLBs-intersects with the flat part of the FBO bank demand curve.

However, actual daily EFFRs from 2010 through 2013 (Chart 1) averaged near the midpoint between the IOER compensation rate of 25 basis points and zero, an outcome that is inconsistent with the simple supply and demand analysis presented in Exhibit 4 . The perfectly competitive assumption-which is largely responsible for predicting a fed funds rate equal to the IOER rate-may, perhaps, be misplaced. For example, institutions in the fed funds market do not face a fed funds rate at which they can borrow or lend as much as they please. Instead they meet in pairs and negotiate a fed funds rate. If both borrowers and lenders have some bargaining power, then one would expect the fed funds rate to lie somewhere in between each of the parties' opportunity costs. The FHLBs' opportunity cost on Fed balances is zero and the FBOs' opportunity cost is the IOER rate-in other words, the highest rate that the FBOs would pay for fed funds. Hence, when parties 
CHART 1

Daily Federal Funds Rate and IOER, Including Month Ends 1/1/2010-12/31/2013

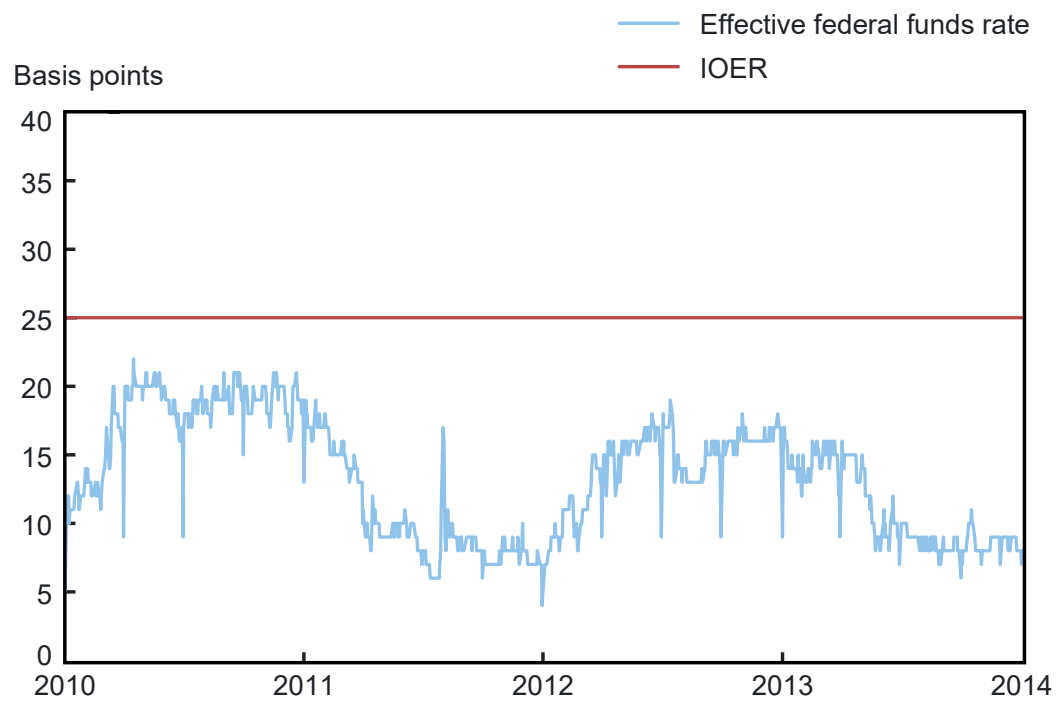

Sources: Federal Reserve Bank of New York; Bloomberg L.P.

bilaterally negotiate a fed funds rate, it should lie somewhere between zero and the IOER rate, as illustrated by point B in Exhibit 4 and consistent with what we observe for the 2010-13 time period.

\subsection{Post-2013}

In September 2013, the FOMC introduced the overnight reverse repurchase facility as an operational exercise to help better control the EFFR within its target range. ${ }^{8}$ The initial cap on propositions submitted in ON RRP operations was quite small, but the cap was increased several times until reaching its current level of $\$ 30$ billion (on individual participants) in September 2014. ${ }^{9}$ Intuitively, the ON RRP rate helps set a floor for overnight rates by providing an outside option for investors that are eligible to participate in ON RRP operations but not eligible for IOER compensation. (See Box 2 on page 11 for a more detailed discussion.) All FHLBs are eligible counterparties for the Fed's ON RRP facility. Post-2013, FHLBs were quite willing to lend fed funds below the IOER rate, but were generally reluctant to lend fed funds below the ON RRP rate. As a result, the supply of reserves provided by FHLBs can be thought of as a line that is horizontal at the ON RRP rate up to the FHLBs' total holdings of reserves and then vertical at that point (Exhibit 5). The ON RRP operation can be interpreted as increasing the opportunity cost of lending by FHLBs from zero to the ON RRP rate. 
ExhiBit 5

Supply of Reserves by Federal Home Loan Banks after Introduction of the Overnight Reverse Repo Facility

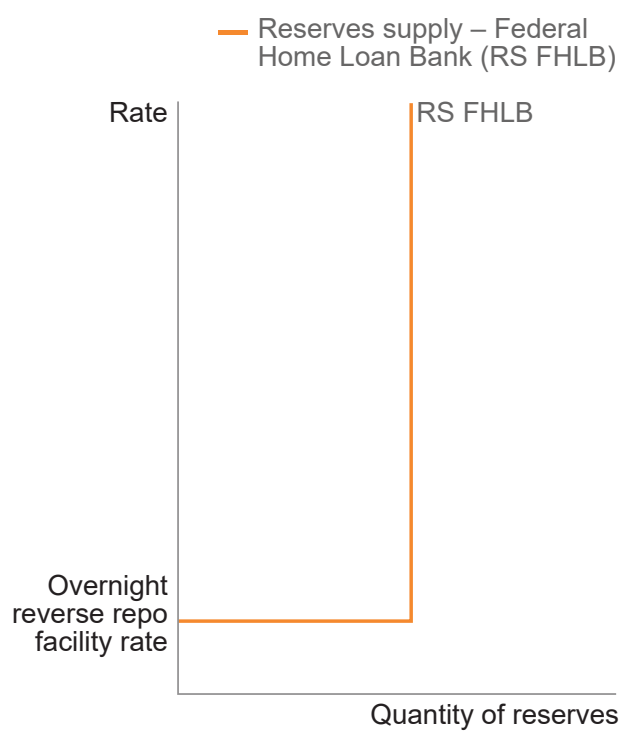

Since FBOs are generally willing to borrow fed funds only at rates below the IOER rate, the equilibrium EFFR that FBOs and FHLBs negotiate should generally fall between the IOER and ON RRP rates, as illustrated in Exhibit 6. The increase in the FHLBs' opportunity cost of lending-from zero to the ON RRP rate-tends to increase the EFFR. The equilibrium EFFR suggested by this stylized explanation is supported by empirical data, as illustrated in Chart 2 . This chart presents the nominal EFFR for all days since 2014, showing that the EFFR remains well contained in the rate corridor suggested by Exhibit 6, bounded above by the IOER rate and below by the ON RRP rate. Chart 2 also displays a "saw-tooth" pattern, evidenced by consistent rate decreases (or softness) on month-end dates, which we discuss in more detail in the next section. The impact of the lower rates evidenced on month-end dates increased EFFR volatility while the EFFR remained inside the target range. In particular, since the pre-crisis corridor, defined by the discount window lending rate and zero, was much larger, one might expect the day-to-day volatility in the EFFR to have then been higher absent the ON RRP facility.

\subsection{What Was Behind the Decline in the EFFR on Month-End and Quarter-End Dates?}

FBOs, like domestic banks, are subject to Basel III capital requirements, which include satisfying a capital adequacy leverage ratio, measured as the ratio of a bank's equity capital to its total assets. The leverage ratio for domestic banks is based on an average of end-of-day total assets for each day in the reporting period, which is typically a calendar quarter. In contrast, many foreign banks calculate their total assets for their reported leverage ratio based on a snapshot 
Exнівіт 6

Equilibrium in the Fed Funds Market after Introduction of the Overnight Reverse Repo Facility

$$
\begin{aligned}
& \text { - Foreign banking organization demand }\left(B D_{F B O}\right) \\
& \text { - Reserve requirements }(R R) \\
& \text { - Reserves supply }(R S) \\
& \text { - } R_{F H L B}+R S=\text { Total reserves supply }\left(R S_{T}\right) \\
& X \text { Equilibrium effective fed funds rate }
\end{aligned}
$$

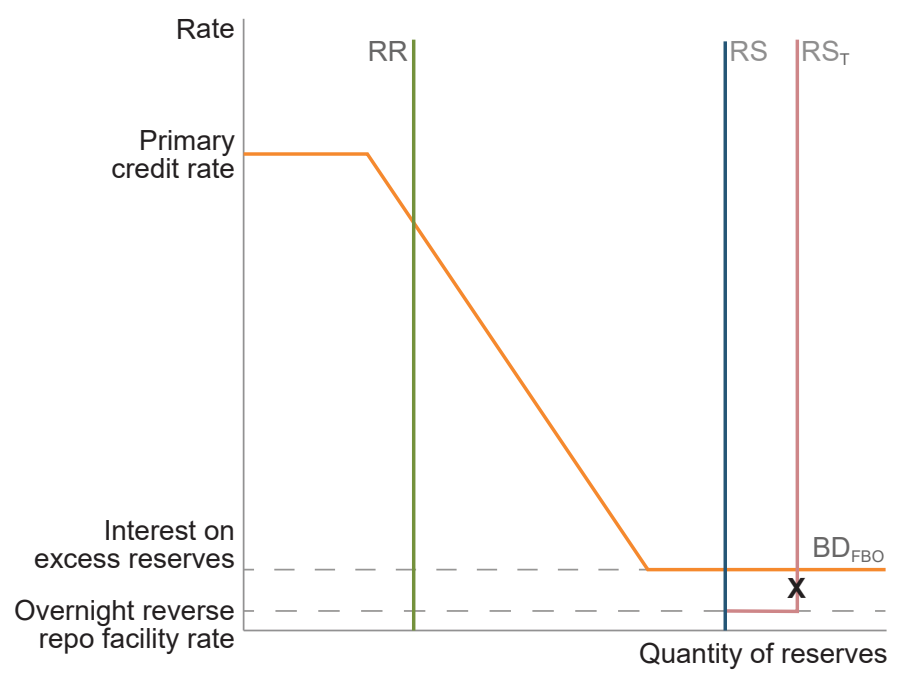

\section{CHART 2}

Selected Overnight Interest Rates

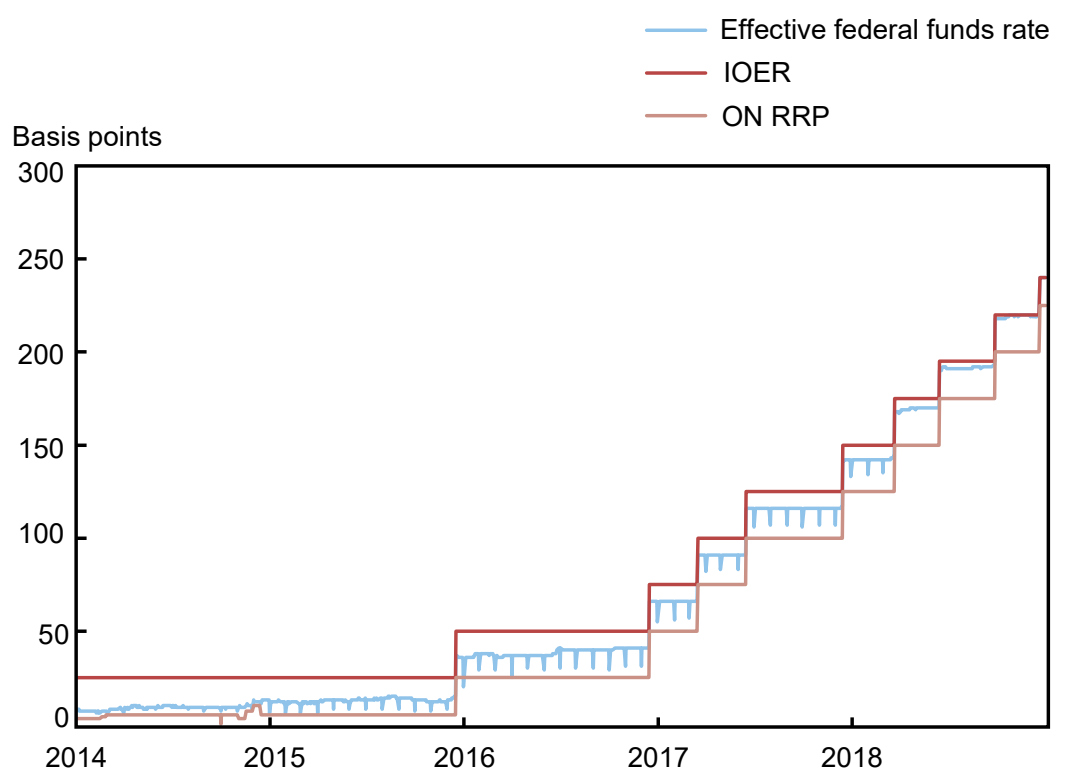

Sources: Federal Reserve Bank of New York; Bloomberg L.P. 
Box 2

$$
\text { The Fed's Overnight Reverse Repo Facility }
$$

When the Desk began conducting ON RRP operational exercises in September 2013, the FOMC stated that ON RRPs could be an effective tool for managing money market interest rates by helping to provide a floor for those rates. Of note, the ON RRP facility allows nonbanks to effectively invest funds at the Fed, thus broadening the scope of the Fed's reach and the Desk's potential impact on money market functioning. Counterparty types that are active users of the facility include money market mutual funds and government-sponsored enterprises, including Fannie Mae, Freddie Mac, and all eleven of the Federal Home Loan Banks.

During the operational exercise time period of September 2013-December 2015, the per-counterparty bid limit of the ON RRP was increased several times. The counterparty cap limits the amount that any one counterparty can invest in the ON RRP facility. A relatively low starting bid limit of $\$ 500$ million in September 2013 was gradually increased to $\$ 30$ billion by September 2014 . An aggregate cap—or maximum allowable take-down amount across all participants—of $\$ 300$ billion was also introduced in September 2014.

Over time, the ON RRP has proven to be successful in forming a floor for short-term rates in the wholesale funding markets. Unlike the pre-crisis repo and reverse repo operations conducted by the Fed, the ON RRP is not intended to drain reserves, but to provide an investment option, primarily to non-IOER-eligible institutions. The ON RRP provides eligible investors with a standing option to invest at the Fed at the ON RRP offering rate. This option helps form a floor on rates, since borrowers know that if they want to borrow funds from ON RRP counterparties, they must offer a rate that is competitive with the ON RRP offering rate. In this regard, the ON RRP can be seen as influencing rates-providing a rate floor-regardless of the amount of take-up in the actual operations.

The ON RRP operational exercises became a full-fledged facility in December 2015 when the FOMC lifted the target range for the policy rate above zero. The aggregate cap was also removed at that time. During the period of abundant reserves, many market participants considered this facility to be a valuable tool in helping the Desk maintain control over short-term interest rates.

of total assets on the quarter-end date only. Calculating the leverage ratio in this way creates an incentive for foreign banks to improve their equity-to-asset ratio by reducing total assets on quarter-end dates. FBOs often reduce their borrowing levels in the fed funds market on quarter-end dates as an effective way to reduce their asset holdings (which include their reserve assets held at the Fed) and improve their leverage ratio metrics.

Because the supply curve for reserves is vertical above the ON RRP rate, this reduction in bank borrowing demand has a relatively pronounced impact on the EFFR, as illustrated in Exhibit 7. Since the leverage ratio can be interpreted as a cost of borrowing, this cost pushes down the FBOs' maximum borrowing rate below the IOER rate, which in turn pushes down the negotiated fed funds rate. Interestingly, this phenomenon occurred from late 2014 through early 2018 on both quarter-end dates and non-quarter-end month-end dates. During this time, market participants generally stated that they faced relatively high balance sheet costs on such dates, which prompted a reduction in the demand to borrow fed funds, leading to lower fed 
Exнiвiт 7

Reserve Demand by FBOs and Equilibrium in the Fed Funds Market on Month-End and Non-Month-End Dates

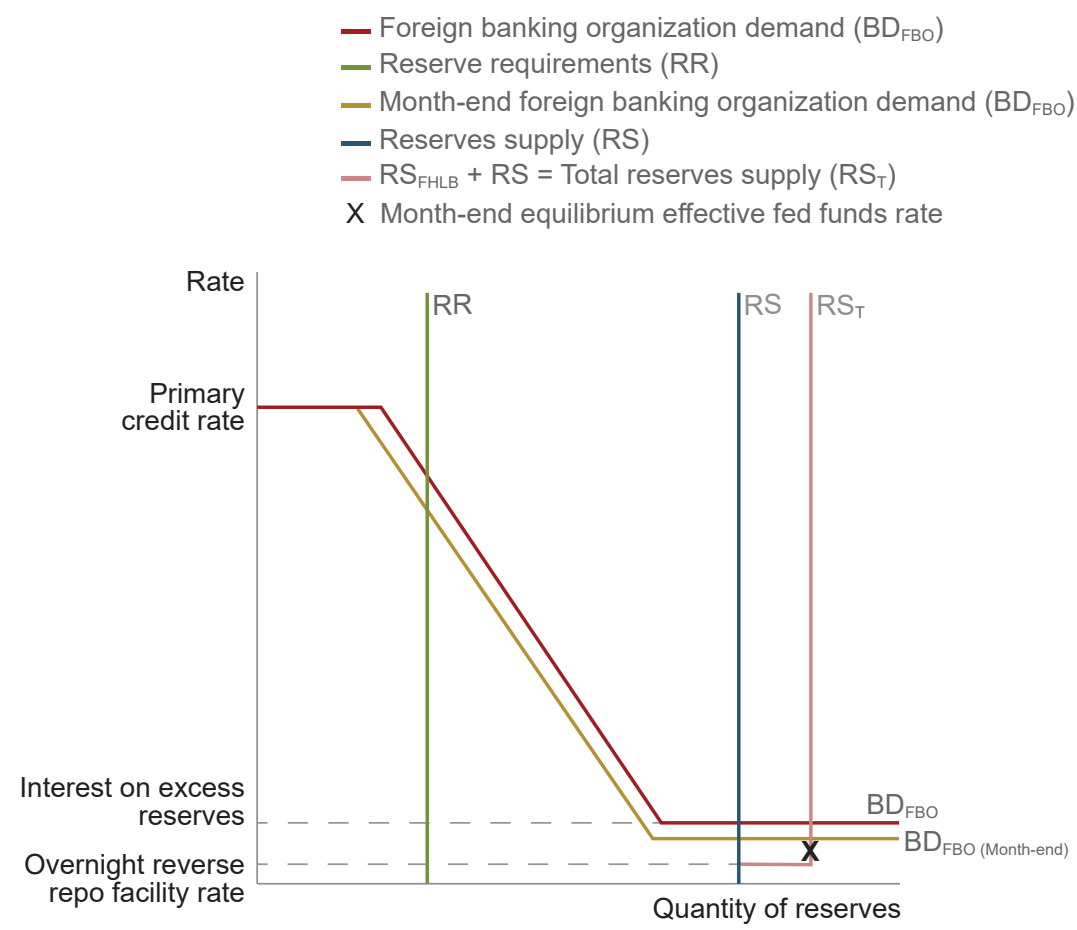

funds rates on month-end dates. With the benefit of hindsight, it appears that market expectations (a so-called belief-driven phenomena, implying that markets behave in a certain way simply because participants come to expect that behavior) played a major role, as the saw-tooth pattern of lower fed funds rates on month-end dates unexpectedly disappeared in March 2018.

\subsection{What Was Behind the Ultralow Volatility in the Fed Funds Market?}

With the exception of month-end dates, the EFFR was remarkably stable during the abundant reserves regime, as shown in Table 1. The table presents the standard deviation of the EFFR, exclusive of month-end dates, for a representative pre-crisis period relative to the varying target ranges from 2014 through March 21, 2018.

A possible contributing factor for the ultralow day-to-day volatility is that in March 2016 the Federal Reserve switched its method for calculating the EFFR from a weighted average mean to a weighted average median. Although computing the central tendency of a distribution by using the median instead of the mean does not necessarily decrease (or increase) the volatility of that measure, medians can have lower volatility than means for distributions that have significant outlier observations. However, a review of the underlying EFFR data for 2017 indicates that the switch from the mean to the median did not have a significant impact on the daily EFFR. ${ }^{10}$ 
TABLE 1

Standard Deviation of Daily EFFRs for Select Target Rate / Ranges

\begin{tabular}{lccc}
\multicolumn{1}{c}{ Time period } & $\begin{array}{c}\text { Rate/Range } \\
\text { Placeholder }\end{array}$ & $\begin{array}{c}\text { Target Rate/Range } \\
\text { (Basis Points) }\end{array}$ & $\begin{array}{c}\text { Standard Deviation } \\
\text { (Basis Points) }\end{array}$ \\
\hline $7 / 1 / 06-6 / 30 / 07$ & & 525 & 3.01 \\
$1 / 1 / 14-12 / 16 / 15$ & $0.00-0.25$ & $0-25$ & 2.28 \\
$12 / 17 / 15-12 / 14 / 16$ & $0.25-0.50$ & $25-50$ & 1.81 \\
$12 / 15 / 2016-3 / 15 / 17$ & $0.50-0.75$ & $50-75$ & 0.00 \\
$3 / 16 / 2017-6 / 14 / 17$ & $0.75-1.00$ & $75-100$ & 0.00 \\
$6 / 15 / 17-12 / 13 / 17$ & $1.00-1.25$ & $100-125$ & 0.13 \\
$12 / 14 / 17-03 / 21 / 2018$ & $1.25-1.50$ & $125-150$ & 0.45
\end{tabular}

Source: Federal Reserve Bank of New York.

Perhaps the best explanation for the historical trend of ultralow day-to-day volatility in the daily EFFR is that abundant reserve borrowers generally did not have a specific target amount in mind for their daily fed funds borrowing activity, in contrast to borrowers in the pre-crisis period. Pre-crisis, both borrowers and lenders had specific daily transaction quantity goals, and rates would adjust based on varying participant perceptions of whether buyers or sellers had more bargaining power at the time the fed funds transactions were executed.

As such, the post-crisis fed funds market during this time can be characterized as having motivated lenders, coupled with borrowers that are not particularly sensitive to either the quantity or price of the reserves they are borrowing. This lack of sensitivity on the part of the borrowers has contributed to the extreme stability in the EFFR post-crisis. Both lenders and borrowers are motivated to maintain their relationships, seeking only to execute at a "fair price." This behavior has led to market pricing that has been remarkably consistent on a day-to-day basis aside from month-end dates, which was not the case pre-crisis.

\subsection{Was the EFFR Well Connected to Other Short-Term Wholesale Funding Rates?}

During the abundant reserves regime, the EFFR consistently fell within the FOMC's target range, with only one outlier observation occurring between the time the target range was adopted in December 2008 and the end of our sample period in March 2018. ${ }^{11}$ Amid very little day-to-day rate volatility, the EFFR remained reasonably well connected to other overnight wholesale funding rates, as shown in Chart 3. Note that the EFFR remained well anchored relative to repo and commercial paper rates, suggesting that the EFFR is able to perform the role of a foundation rate for the fixed-income yield curve, just as it did during 
Chart 3

Construction of Money Market Rates Over Time
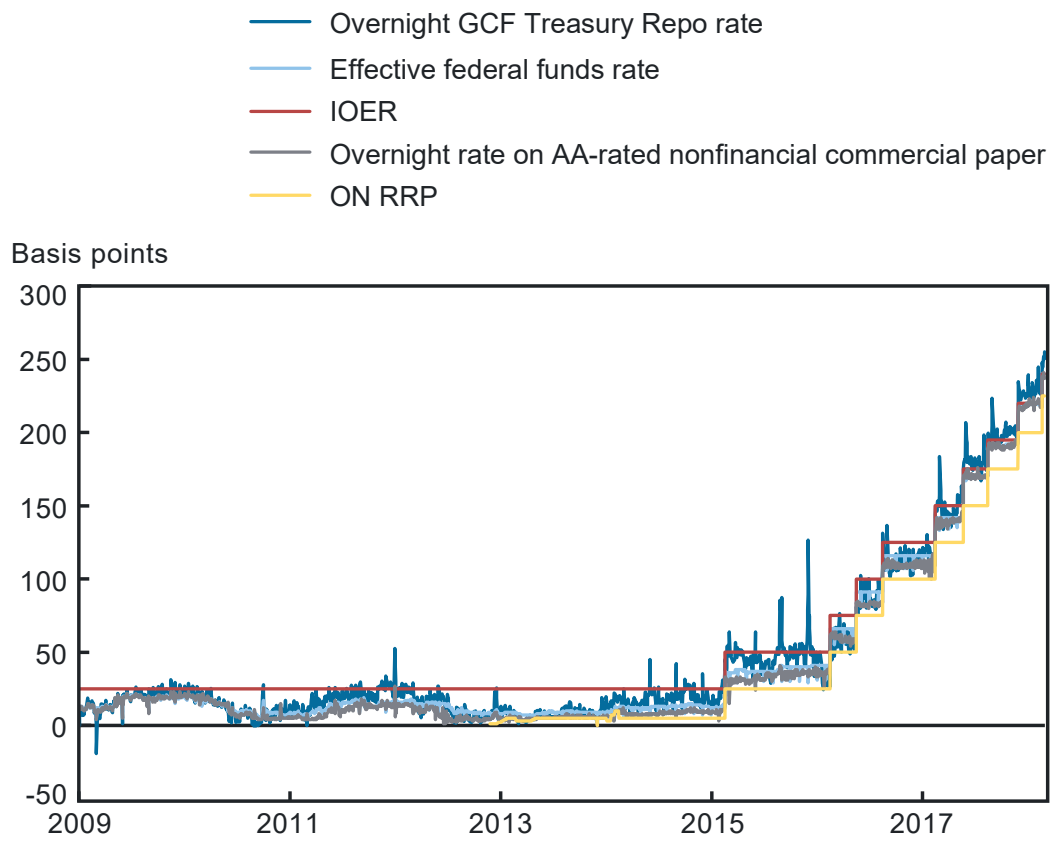

Sources: Federal Reserve Bank of New York; Bloomberg L.P.

Note: Excludes December 31, 2018.

the pre-crisis period. That said, one cannot overstate the importance of the IOER and ON RRP rates in this process, as they formed upper and lower bounds for the EFFR when excess reserves were abundant.

\section{Summary}

In this article, we describe the functioning of the federal funds market during the recent period of abundant excess reserves and show that it was significantly different from that of the pre-crisis period. We discuss market dynamics post-crisis through early 2018 and provide several reasons for the day-to-day stability that emerged in fed funds market trading. Through it all, the fed funds market continued to be representative of other overnight, wholesale funding markets. 


\section{Notes}

The authors thank Darrian Robinson and Logan Suba for chart preparation.

1 "Federal funds" is defined by Federal Reserve Regulation D.

${ }^{2}$ Prior to March 2016, the EFFR was calculated as a volume-weighted average rate of fed funds trades, as reported by fed funds brokers. Post-2016, the rate is calculated as a volume-weighted median based on transactions, as reported in the FR2420 Report of Selected Money Market Rates.

${ }^{3}$ In practice, some banks chose to hold significant levels of clearing balances to supplement their required reserve levels. The Desk managed reserve levels to meet required operating balances, which were equal to reserve requirements plus clearing balances. Banks were compensated on their clearing balances based on three-month Treasury bill rates. Clearing balances provided banks with increased flexibility in holding reserves across the maintenance period. For simplicity, we refer to "required operating balances" as "reserve requirements" for the remainder of this article.

${ }^{4}$ The major categories of autonomous factors are the Treasury General Account balance, currency in circulation, "float," and changes in repo investments offered to the Desk's foreign central bank customers. Float is a temporary increase, or decrease, in Federal Reserve liabilities that results in a timing difference in check processing-from when funds are debited from one bank's account and credited to the other bank's account.

${ }^{5}$ Reserve requirements are calculated based on a two-week period beginning on a Monday and ending on a Friday. Reserve balances against these requirements are calculated over a two-week period starting on the subsequent Thursday and ending on a Wednesday. Fed funds market participants were watchful for elevated volatility to occur every other Wednesday, on reserve period settlement day.

${ }^{6}$ The New York Fed's Central Bank and International Account Services (CBIAS) area provides fiduciary and custodial services to foreign central banks. CBIAS offers an investment product known as the "foreign repo pool," which appears in the H.4.1 statistical release "Factors Affecting Reserve Balances of Depository Institutions and Condition Statement of Federal Reserve Banks" (Federal Reserve balance sheet) as Reverse repurchase agreements; foreign official and international accounts (https://www.federalreserve.gov/releases/h41/current/). With this investment, CBIAS customers purchase securities from the SOMA and agree to resell the securities the next day at a higher price that reflects de facto interest on the amount invested. The TGA represents reserve balances of the Treasury that are kept overnight at the Federal Reserve.

${ }^{7}$ To transact in the fed funds market, participants need an account at the Federal Reserve. The selected deposit and Eurodollar time deposit markets are similar to the fed funds market in that they are both unsecured, primarily overnight funding markets in which the rate is negotiated daily. Only fed funds transactions are included in the EFFR. The overnight bank funding rate (OBFR) includes fed funds, Eurodollars, and selected deposits.

${ }^{8}$ After the crisis, the FOMC began expressing its policy stance in terms of a fed funds target range instead of a target rate.

${ }^{9}$ Given the low initial proposition limits, this article considers January 1, 2014, to be the start of the ON RRP exercise.

${ }^{10}$ Specifically, had the mean been used instead of the median, the EFFR would not have changed by more than one basis point on any single date. For a discussion of the decision to change the calculation from the mean to the median, see "Technical Note Concerning the Methodology for Calculating the Effective Federal Funds Rate," https://www. newyorkfed.org/medialibrary/media/markets/EFFR-technical-note-070815.pdf.

11 The one exception was when the EFFR rate for the 2015 year-end date was five basis points below the target range. Volatility on period-end dates is a common money market phenomena. 